\title{
iDirac: a field-portable instrument for long-term autonomous measurements of isoprene and selected VOCs
}

\author{
Conor G. Bolas ${ }^{1}$, Valerio Ferracci ${ }^{2}$, Andrew D. Robinson ${ }^{3}$, Mohammed I. Mead ${ }^{2}$, Mohd Shahrul Mohd Nadzir ${ }^{4}$, John \\ A. Pyle ${ }^{1,5}$, Roderic L. Jones ${ }^{1}$, and Neil R. P. Harris ${ }^{1,2}$ \\ ${ }^{1}$ Department of Chemistry, University of Cambridge, Lensfield Road, Cambridge, CB2 1EW, UK \\ ${ }^{2}$ Centre for Environmental and Agricultural Informatics, Cranfield University, College Road, Cranfield, MK43 0AL, UK \\ ${ }^{3}$ Schlumberger Cambridge Research, Madingley Road, Cambridge, CB3 0EL, UK \\ ${ }^{4}$ School of Environmental and Natural Resource Sciences, Universiti Kebangsaan Malaysia, \\ 43600, Bangi, Selangor, Malaysia \\ ${ }^{5}$ National Centre for Atmospheric Science, University of Cambridge, Cambridge, UK
}

Correspondence: Neil R. P. Harris (neil.harris@cranfield.ac.uk)

Received: 29 May 2019 - Discussion started: 1 July 2019

Revised: 3 January 2020 - Accepted: 14 January 2020 - Published: 19 February 2020

\begin{abstract}
The iDirac is a new instrument to measure selected hydrocarbons in the remote atmosphere. A robust design is central to its specifications, with portability, power efficiency, low gas consumption and autonomy as the other driving factors in the instrument development. The iDirac is a dualcolumn isothermal oven gas chromatograph with photoionisation detection (GC-PID). The instrument is designed and built in-house. It features a modular design, with the novel use of open-source technology for accurate instrument control. Currently configured to measure biogenic isoprene, the system is suitable for a range of compounds. For isoprene measurements in the field, the instrument precision (relative standard deviation) is $\pm 10 \%$, with a limit of detection down to $38 \mathrm{pmol} \mathrm{mol}^{-1}$ (or ppt). The instrument was first tested in the field in 2015 during a ground-based campaign, and has since shown itself suitable for deployment in a variety of environments and platforms. This paper describes the instrument design, operation and performance based on laboratory tests in a controlled environment as well as during deployments in forests in Malaysian Borneo and central England.
\end{abstract}

\section{Introduction}

Isoprene $\left(\mathrm{C}_{5} \mathrm{H}_{8}\right)$ is one of the most important non-methane biogenic volatile organic compounds (BVOC) emitted into the atmosphere. It has a global emission rate estimated at around $500 \mathrm{TgC} \mathrm{yr}^{-1}$ (Guenther et al., 2006), and its oxidation products make it a major factor determining ozone and secondary organic aerosol (SOA) production. Emitted by vegetation, it has been linked to temperature regulation, reducing drought-induced stress and other physiological processes within plants (Sharkey, 2013; Sharkey et al., 2008). A dialkene, isoprene is prone to oxidation by reaction with the hydroxyl radical $(\mathrm{OH})$ as well as by ozonolysis and reaction with the nitrate radical $\left(\mathrm{NO}_{3}\right)$ (Stone et al., 2011). Isoprene oxidation pathways are complex (Archibald et al., 2010) and result not only in a number of oxygenated volatile organic compounds (OVOCs e.g. formaldehyde, methacrolein and methyl vinyl ketone) but also in a suite of low-volatility stable products and intermediates that can act as precursors of secondary organic aerosols (Carlton et al., 2009; Claeys, 2004; Liu et al., 2016). As a result of its high reactivity and large emissions, determining the global abundance of isoprene is important to understand the oxidising capacity of the atmosphere (Squire et al., 2015) and the formation of SOA, which can affect the optical properties of the atmosphere and, in turn, impact the climate (Carslaw et al., 2010).

Due to its high reactivity, isoprene is relatively short-lived, with a typical lifetime of the order of $1 \mathrm{~h}$ in a temperate forest (Helmig et al., 1998). Isoprene emissions are mainly driven by incoming solar radiation and temperature, and, as a result, they exhibit a distinctive diurnal cycle which peaks around midday. Local abundances can change rapidly in response to 
meteorological variations, such as changes in incoming photosynthetically active radiation (PAR), temperature and atmospheric dynamics (Langford et al., 2010). High time resolution data are required to capture trends in isoprene concentrations in real time. It is expected that isoprene emissions will be affected by global change (increasing temperatures, land use change and increasing $\mathrm{CO}_{2}$ ) in the coming decades (Bauwens et al., 2018; Hantson et al., 2017; Squire et al., 2015). However, the overall magnitude and sign of changes in isoprene emissions are still uncertain due to the many variables at play and the uncertainties in our emission models. This, coupled with its large variability, makes it highly desirable to improve the temporal and spatial coverage of isoprene measurements so that our understanding of its emissions via models can be validated against field data.

Measurements of atmospheric hydrocarbons such as isoprene are challenged by the difficulty in making measurements in remote places. To date, in situ measurements of isoprene have been carried out using existing commercial bench-top instruments, such as gas chromatographs (Jones et al., 2011) and mass spectrometers (Noelscher et al., 2016; Yáñez-Serrano et al., 2015). These techniques differentiate between VOCs either by separation (gas chromatography) or by identification of their molecular ions based on mass-tocharge ratios (mass spectrometry). These instruments, while offering high precision and stability, are not built to withstand field conditions for long periods of time due to their need for power, temperature-controlled environments and speciality carrier gases. This is especially true in under-sampled regions of high isoprene emissions, which are typically in remote or challenging environments (e.g. tropical forests). In these locations, instrument size, portability, autonomy, power demand and gas consumption severely limit the length of a deployment. In addition, instrument cost and maintenance limit the number of instruments deployed at any one time, and, hence, the spatial coverage of a field campaign.

An alternative method to detect environmental VOCs is with grab samples (Robinson et al., 2005). These can either be whole air samples or adsorbent tubes, where air samples (or some specific air components) are collected in an inert vessel and analysed at a later date. While grab samples can be deployed in relatively large numbers, they typically provide low temporal resolution, making this approach unsuitable to capture the rapidly changing concentrations of isoprene. In addition, reactive compounds can degrade over time before analysis, and using this method for long periods, even with some degree of automation, is very time and resource intensive. Recent work showed that it is possible to retrieve isoprene abundances in the boundary layer using satellite measurements by means of thermal infrared imaging (Fu et al., 2019). However, with uncertainties between $10 \%$ and $50 \%$, these retrievals would benefit from further validation from ground-based instrumentation.
All of the limitations in the instruments currently used for VOC detection drive the need for a field instrument that has the following six qualities:

1. lightweight, so that it is portable and can easily be carried and installed in environments difficult to access with traditional instrumentation;

2. low-power, so that it is capable of running off-grid, allowing measurements in locations with no mains power;

3. autonomous, so that it minimises operator involvement and maintenance;

4. low gas use, so that it minimises the cylinder size required and the number of site visits to replace gas cylinders;

5. rugged and durable, so that it can withstand challenging environments; and

6. relatively low-cost, so that many instruments can be deployed at one time, maximising spatial coverage.

Here we describe the development and validation of the iDirac, an instrument that fulfils the requirements listed above. It follows on from the philosophy of the $\mu$ Dirac (Gostlow et al., 2010), with portability, modularity, power efficiency and autonomy at the centre of its design. The iDirac also incorporates inexpensive microcontroller board processors for advanced control and remote access to the instrument. The core GC instrument and its operation are described in Sect. 2, while Sect. 3 presents the software used to control the instrument. Instrument performance is discussed in Sect. 4, including calibration, accuracy, precision, sensitivity and separation ability. Finally, results from trial runs in a controlled laboratory environment and deployments in Malaysian Borneo and central England are presented in Sect. 5. Results on the impact of herbivory on canopy photosynthesis and isoprene emissions in a UK woodland (Visakorpi et al., 2018) and on isoprene concentrations near the Antarctic Peninsula (Nadzir et al., 2019) have already been published.

\section{Practical description of the iDirac}

The iDirac is a portable gas chromatograph equipped with a photoionisation detector (GC-PID): the VOCs in an air sample are separated on chromatographic columns and then sequentially detected by the PID. The instrument is built inhouse and is lightweight, low-power and able to operate for up to several weeks or months autonomously. Its specifications are shown in Table 1. Section 2.1 describes the basic outline of the instrument, and Sect. 2.2 describes the specific configuration of the instrument for isoprene. 


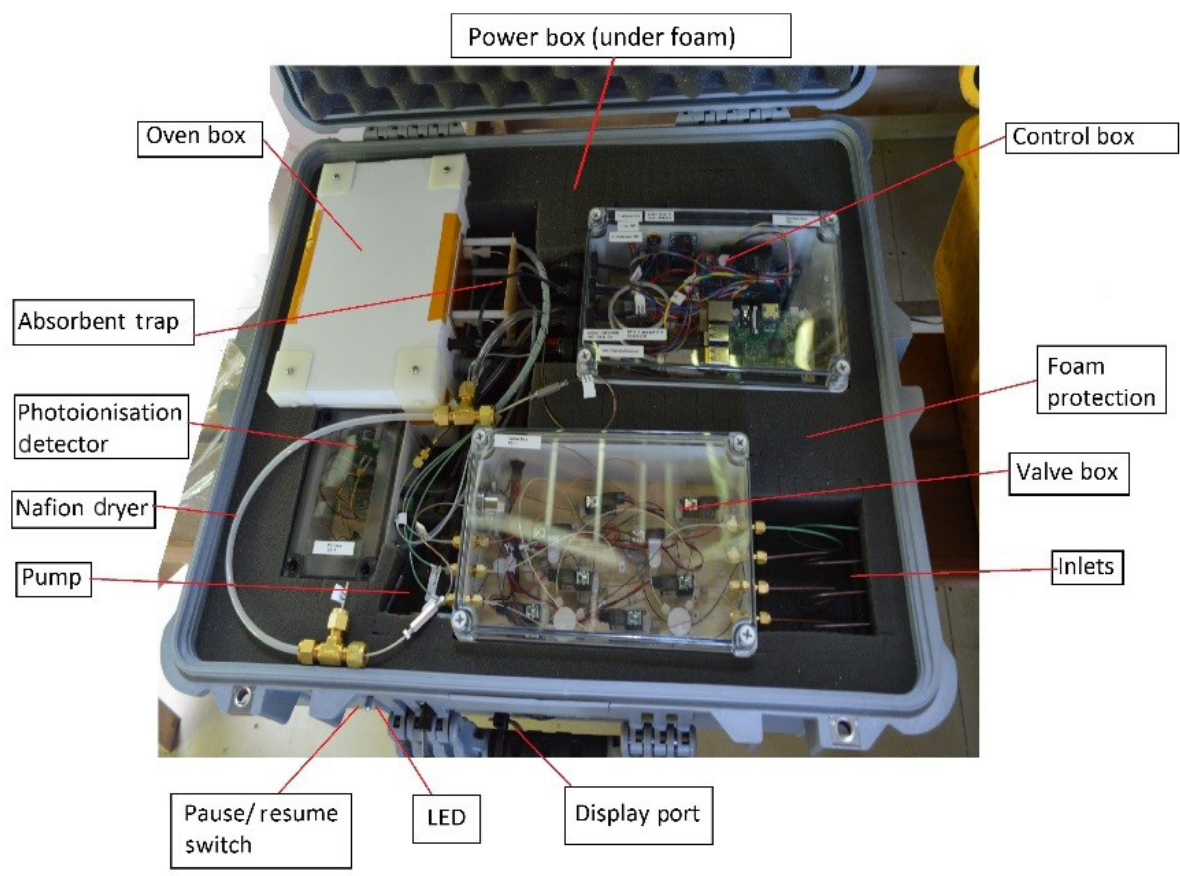

Figure 1. Interior of the iDirac showing the modular design of its component parts inside the main Peli case $(22 \mathrm{~cm} \times 61.6 \mathrm{~cm} \times 49.3 \mathrm{~cm})$

Table 1. iDirac specifications.

\begin{tabular}{|c|c|}
\hline Power & $12 \mathrm{~W}$ \\
\hline Weight & $10 \mathrm{~kg}$ \\
\hline Voltage requirements & $10-18 \mathrm{~V}$ \\
\hline Dimensions & $22 \mathrm{~cm} \times 61.6 \mathrm{~cm} \times 49.3 \mathrm{~cm}$ \\
\hline Carrier gas & $\begin{array}{l}\text { High-purity nitrogen } \\
\text { (grade 5.0, or } 99.999 \% \text { ) }\end{array}$ \\
\hline Calibration gas & $\begin{array}{l}10 \mathrm{nmol} \mathrm{mol}^{-1} \text { (or ppb) } \\
\text { high-accuracy isoprene in nitrogen }\end{array}$ \\
\hline Limit of detection & $38 \mathrm{pmol} \mathrm{mol}^{-1}$ (or ppt) \\
\hline Precision & $11 \%$ \\
\hline
\end{tabular}

\subsection{Core gas chromatograph physical design}

The iDirac is built in a modular fashion, so that the various components are housed in six main plastic boxes (Piccolo polycarbonate enclosures, IP67) packed in foam inside a protective waterproof case (Peli 1600), as shown in Fig. 1. Details on the boxes and their contents are given below, and shown within the instrument in Fig. 1. The set-up is comprised of the following:

- a valve box, containing eight solenoid valves to control gas flow from the four inlets;
- a control box, containing microcontroller boards (Arduino and Raspberry Pi), a number of electronic components (e.g. solid state relays), the flowmeter and an SD card for data storage;

- an oven box, containing the dual-column system, (preand main columns), heating element and Valco valve;

- a PID box, containing the photoionisation detector (PID);

- a pump box, containing the pump and pressure differential sensor;

- and a power box, containing power regulators and electrical fuses.

On the exterior, the iDirac has a power socket and four inlets for gas input. The inlets are for the nitrogen carrier gas, a calibration gas and two sample lines (samples 1 and 2) between which the instrument can alternate.

The general pneumatic design of the instrument is built around two phases in the analysis cycle which are represented schematically in Fig. 2: a loading phase (load mode - pink), in which the analyte of interest is pre-concentrated on an adsorbent trap, and an injection phase (inject mode - purple), in which the analyte is desorbed from the trap and directed into the oven for separation and, eventually, detection. These two modes are controlled by a two-way 10port Valco valve (VIDV22-3110, mini diaphragm 10-port 2position $1 / 16^{\prime \prime} 0.75 \mathrm{~mm}$, Thames Valco) in the oven box, 


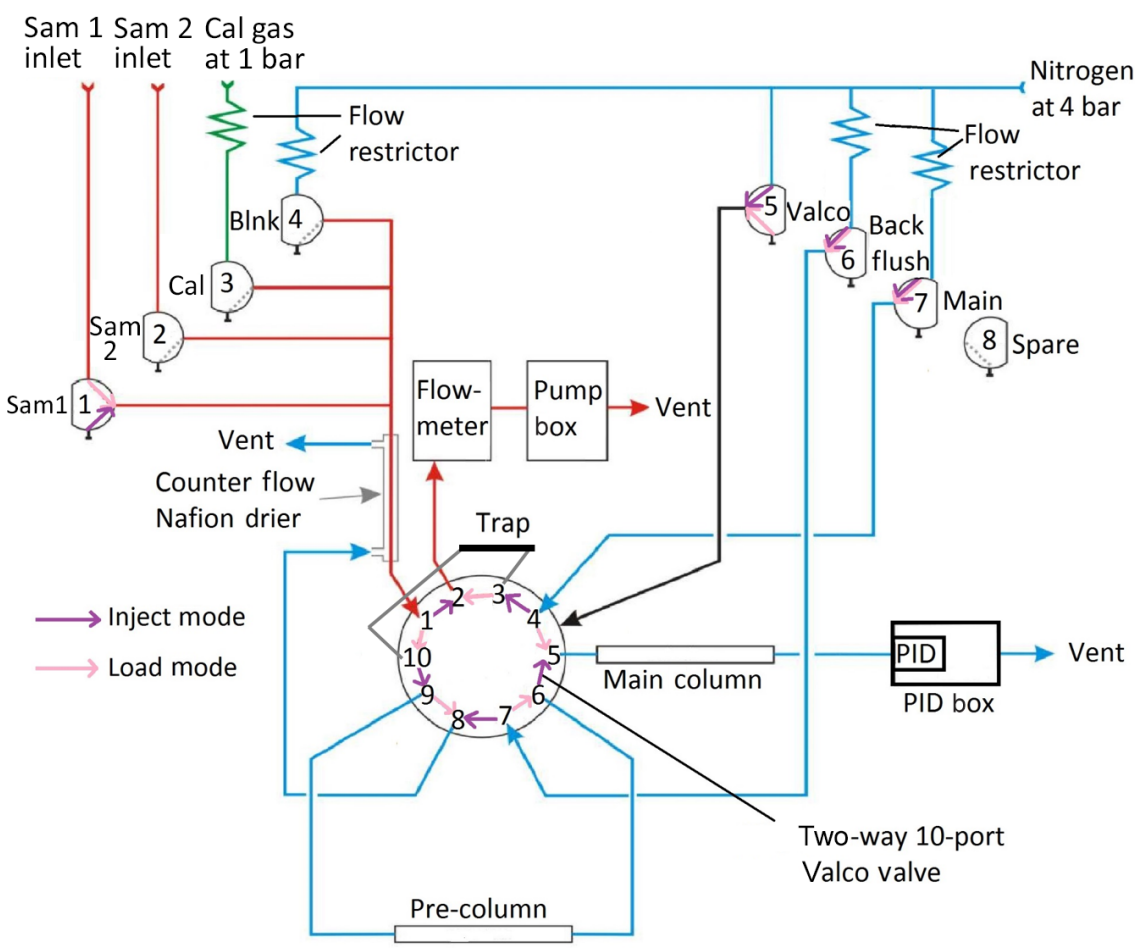

Figure 2. Schematic representation of the iDirac operation. When in load mode (valve 5 off - pink), the contents of a gas source chosen between valves 1, 2, 3 and 4 are pre-concentrated on the adsorbent trap. In inject mode (valve 5 on - purple), the VOCs in the trap are injected into the dual-column system for separation and, eventually, detection. ("Sam" refers to sample, "Cal" refers to calibration and "Blnk" refers to blank.)

which is activated by pneumatic actuation, by the set of solenoid valves in the valve box and by the pump.

In load mode (Valco valve not activated, i.e. valve 5 off), one of four inlet gases (either Sample 1, Sample 2, the calibration gas or the blank gas) is selected by switching on the appropriate solenoid valve (valves $1,2,3$ or 4 respectively). By activating the pump, gas is drawn through the selected inlet valve, dried in a Nafion counterflow system and passed through an adsorbent trap where the analyte is preconcentrated. The sampled gas is vented into the Peli case and then to the outside. A flowmeter is placed in series with the sample flow and measures the gas flow through the trap. Once a pre-defined volume of gas has been sampled, the pump stops and the instrument enters inject mode. Laboratory tests found no statistically significant difference in the isoprene peak area between runs using the drier and runs bypassing it.

In inject mode, the trap is flash-heated to $300 \pm 5^{\circ} \mathrm{C}$ for $9 \mathrm{~s}$ to desorb the analyte from the adsorbent material. The Valco valve is then pneumatically activated by switching valve 5 on: the nitrogen carrier is flowed through the trap in the direction opposite to trap-loading, delivering the desorbed compounds into the dual-column system where they undergo chromatographic separation. The oven consists of a pre-column, which screens for large molecules (e.g. the monoterpenes) whilst allowing smaller molecules through, and a main column, which performs the critical separation of the relevant analytes. The main column eluent is incident on the PID membrane, where the signal from the changing composition of the gas exiting the main column is detected.

More details on the individual parts of this cycle are given below.

\section{Inlet manifold and sample preparation}

The inlet ports protrude from the side of the Peli case via $1 / 16^{\prime \prime}$ bulkhead unions (Swagelok) and connect directly to the valve box, containing eight solenoid valves that act as gas selectors. The Sample 1 (via valve 1), Sample 2 (via valve 2), calibration gas (via valve 3 ) and blank nitrogen (via valve 4) lines are all combined in a four-way SilcoNert-treated stainless steel Valco manifold (Z4M1, 1/16" manifold, four inlets, Thames Restek). This manifold leads to the adsorbent trap via a Nafion dryer (Nafion gas dryer 12", polypropylene, Perma Pure MD-050-12P-2) which drives excess water vapour out of the gas flow by diffusion through a membrane with a counterflow of dry high-purity nitrogen. Valve 5 is a direct line from the nitrogen inlet to the Valco valve for actuation, which requires a higher pressure (typically 4 bar). Valves 6 and 7 control the nitrogen flow through the columns: valve 7 activates the nitrogen flow through both columns in inject mode (when valve 5 is on), and through 
the main column only in load mode (when valve 5 is off). Valve 6 activates the nitrogen flow through the pre-column for the back-flush in load mode. The nitrogen counterflow needed for the Nafion dryer is provided by valve 6 in inject mode and by the pre-column back-flush vent in load mode. Gas lines downstream from valves 5, 6 and 7 leave the box via manifolds on the side of the box. Valve 8 is a spare valve with no current function.

Flow restrictors upstream from valves 3, 4, 6 and 7 ensure that the flow from the pressurised inlet lines does not exceed the maximum flow through the flowmeter, and they also reduce the gas demand of the instrument. The restrictor tubing used for the calibration line is red PEEK flow restrictor $\left(1 / 32^{\prime \prime} \mathrm{OD}, 0.005^{\prime \prime} \mathrm{ID}\right)$, and the one used for the nitrogen lines is black PEEK (1/32" OD, $0.0035^{\prime \prime}$ ID). The rest of the tubing is SilcoNert-treated stainless steel (Thames Restek, $\left.1 / 16^{\prime \prime} \mathrm{OD}, 0.04^{\prime \prime} \mathrm{ID}\right)$, which does not restrict the gas flow.

\section{Sample adsorption/desorption system}

From the Nafion drier, the sample gas passes through ports 1 and 10 of the Valco valve and into the adsorbent trap when the instrument is in load mode. The trap consists of wide-bore stainless steel tubing (Hichrom, 1/16" OD, 0.046" ID) containing one bed of adsorbent material between two beds of glass beads, both crimped in place, with a coiled nichrome wire heating element surrounding the section of the tube corresponding to the adsorbent. The nichrome wire has a ceramic electrically insulating coating to prevent shorting with the trap tubing. The adsorption of isoprene and other VOCs takes place on a bed of approximately $10 \mathrm{mg}$ Graphsphere 2016 (formerly Carboxen 1016, Supelco, 60/80 mesh, 11021-U); Graphsphere 2016 is a carbon molecular sieve that has been selected for its optimised recovery rate of unsaturated short chain hydrocarbons upon thermal desorption. Different sorbent materials can be used for other species. The gas exiting the trap, now scrubbed of VOCs, flows via ports 3 and 2 on the Valco valve into the flowmeter (Sensirion, ASF1430), which monitors the flow rate through the trap. This is then integrated across the duration of sampling to calculate the total volume of gas sampled. When the desired volume (as specified by the user in the configuration step - see Sect. 3) is reached, the valves from the sample inlet are closed and the pump is halted to stop the flow of gas through the trap. The heating coil is flash-heated to desorb the analyte from the adsorbent, while the Valco valve is switched to inject mode and valve 7 is activated, flushing the desorbed VOCs onto the pre-column in the oven box with the high-purity nitrogen carrier.

\section{Isothermal oven}

The flow containing the sample leaves the trap and enters the thermally insulated oven box. This enclosure, housed in insulating material (lightweight display board, Kerbury Group), is heated to $40{ }^{\circ} \mathrm{C}$ using a heating element (PTC element enclosure heater, $15 \mathrm{~W} 12-24 \mathrm{~V} 40 \mathrm{C}$ ) which is fixed to the baseplate of the oven using conductive paste. A fan mixes the air inside the oven to ensure a uniform temperature throughout. The oven temperature exhibits diurnal variations (typically in the range of $\pm 2{ }^{\circ} \mathrm{C}$ ) that appear to be driven by ambient temperature. This introduces some variability in the isoprene retention time, but it is accounted for in the analysis of chromatograms (see Sect. 3.3).

The sample is injected onto the pre-column (5\% RT-1200, $1.75 \%$ BENTONE 34, SILPT-W, 100/120, $1.0 \mathrm{~mm}$ ID, $1 / 16^{\prime \prime}$ OD SILCO NOC, custom packed, Thames Restek, $70 \mathrm{~cm}$ in length) via ports 9 and 10 on the Valco valve. Here, isoprene and other small molecules travel faster through the pre-column than bulky VOCs. After a set time (typically, $30 \mathrm{~s}$ ), once isoprene has passed through the pre-column, the Valco valve is switched off, with valve 5 closing and valve 6 opening, so that the pre-column is back-flushed. Thus, lighter species, including isoprene, elute onto the main column, whereas larger molecules that are still in the pre-column when valve 5 is switched off are removed from the column system via the back-flush. This is important to avoid large, less volatile species from entering the main column.

The main chromatographic separation occurs on the main column (OPN-RESL-C, 80/100, $1 \mathrm{~mm}$ ID, 1/16"OD, SILCO NOC, custom packed, Thames Restek, $\sim 70 \mathrm{~cm}$ in length), based on the boiling point and polarity of the VOCs. This way, different species elute onto the detector at different times.

\section{Photoionisation detection system}

The sample is directed from the outlet of the main column into a photoionisation detector (PID). The PID (Alphasense Ltd, PID-AH) operates by ionising any gas diffusing through a membrane covering a krypton lamp. Near-vacuum UV radiation from the lamp ionises any molecule with an ionisation potential of less than or equal to $10.6 \mathrm{eV}$. Isoprene, with an ionisation potential of $8.85 \mathrm{eV}$ (Bieri et al., 1977), is readily photolysed and, hence, detected by the PID with a sensitivity of $140 \%$ relative to that of isobutylene, which is used by the manufacturer as a reference compound in terms of PID response. The ions generated by photoionisation produce a voltage change across an electrode system which is converted to a digital signal by an analogue to digital converter (ADC; 16 bit ADC four channel, Adafruit). The PID is turned on for the duration of the elution from the dual-column system, and the data are collected at a frequency of $5 \mathrm{~Hz}$. The chromatography run finishes once isoprene has eluted from the main column (typically 60-75 s after starting the back-flush). The data from the PID are then saved to a new file on an SD card by the Arduino Mega. A typical chromatogram showing an isoprene peak is displayed in Fig. 3. 


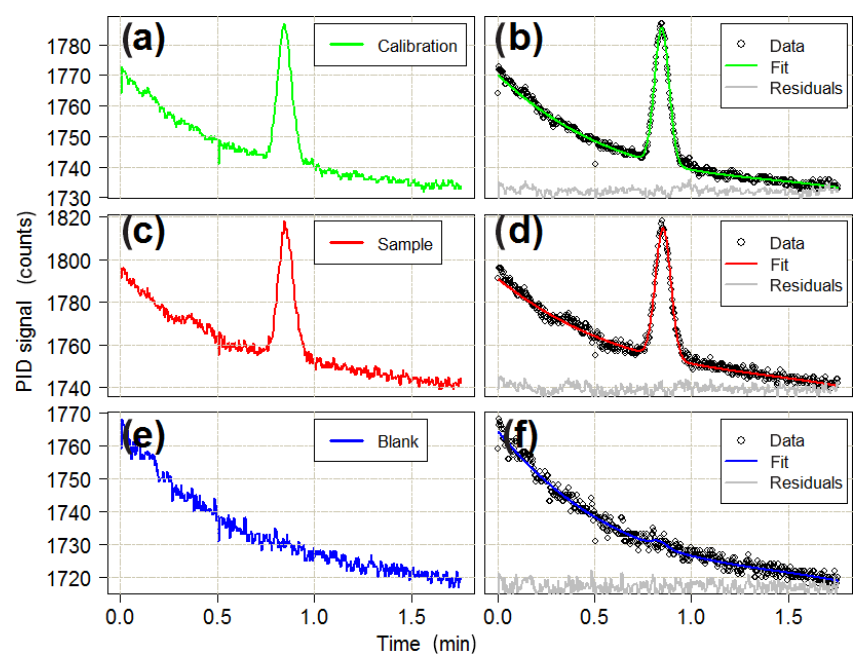

Figure 3. Typical chromatograms for (a) calibration, (c) sample and (e) blank runs. The isoprene peak detected by the PID is around the 0.8 min mark. Panels (b), (d) and (f) show the combined baseline and Gaussian fits to the observed data for each run type. Residuals are offset for clarity. All of the chromatograms are from the deployment in the Wytham Woods field campaign (see Sect. 5.3). The calibration run is for $12 \mathrm{~mL}$ of a $11.6 \mathrm{ppb}$ standard of isoprene in a nitrogen balance. The sample run is for a $150 \mathrm{~mL}$ ambient air sample (later quantified as $1.5 \mathrm{ppb}$ isoprene). The blank run is for a $12 \mathrm{~mL}$ sample of grade 5.0 nitrogen.

\subsection{Instrument operation specifications}

\section{Carrier gas and calibration gas}

Two gas cylinders are required to operate the iDirac: a pure nitrogen supply and a calibration gas. Nitrogen is used as carrier gas through the dual-column system, as sample gas for the blank runs and also to actuate the Valco valve. The nitrogen supply is of at least grade 5 purity (corresponding to $\geq 99.999 \%$ nitrogen) to minimise interference from impurities with the detection of isoprene. Typically, we use high-purity Nitrogen BIP (Air Products). The logistics of the measurement dictate the size of the nitrogen cylinder used: for mobile deployments in the field, small portable cylinders $(1.2 \mathrm{~L})$ are ideal; whereas larger cylinders $(10 \mathrm{~L})$ are more suitable for long-term measurement, as they minimise the need for maintenance visits to replace the nitrogen cylinder. Typically, the iDirac can run continuously on a $10 \mathrm{~L}$ nitrogen cylinder supplied at 200 bar for approximately 2 months. The calibration gas consists of a binary gas mixture of approximately $10 \mathrm{nmol} \mathrm{mol}^{-1}$ (or ppb) isoprene in a nitrogen balance stored in a SilcoNert-treated $500 \mathrm{~mL}$ stainless steel cylinder (Sulfinert sample cylinder, TPED, 1/4", Thames Restek). The use of cylinders with passivated internal walls minimises the adsorption of isoprene on surfaces, which would introduce biases in the measurement. The accurate concentration of the calibration gas is determined by comparison with a primary gas standard. The calibration routine is described in detail in Sect. 4.1.

\section{Power requirements for operation}

The instrument requires a power supply between 9 and $18 \mathrm{~V}$. This can either be mains power or, alternatively, a battery. The incoming power is smoothed and regulated with two regulators to stable 5 and $12 \mathrm{~V}$ outlets. The Arduino board monitors the supplied voltage in between runs in the case of the battery losing charge or power cuts. If the voltage drops, the iDirac switches to a power-save mode, where the oven, PID and valves are turned off to conserve power and the instrument waits for $20 \mathrm{~min}$ before again checking the input voltage. Once a high enough voltage (typically $9 \mathrm{~V}$ ) is detected, the various components are turned on again.

\section{Flow control through the instrument}

The flow through the instrument is driven by either upstream pressure (in the case of the nitrogen and calibration gas flows) or by the pump box (in the case of samples 1 and 2). The pump box is an air-tight container with an inlet line and a vent. A diaphragm pump (DF-18, BOXER) withdraws air from the pump box and vents it outside, reducing the pressure inside the enclosure. The reduced pressure within the pump box causes air (from the Sample 1 and Sample 2 inlets) to be drawn through the system, via the trap and the flowmeter. A pressure sensor (differential pressure sensor, Phidgets) monitors the pressure differential between the inside and the outside of the pump box. During a pump cycle, the pump is only activated when the pressure differential falls below a prespecified value (nominally $20 \mathrm{kPa}$ ). This method ensures a uniform flowrate and enables control over low flowrates $\left(\sim 20 \mathrm{~mL} \mathrm{~min}^{-1}\right)$, thus reducing the uncertainty in the volume integration of the air sampled.

\section{3 iDirac software and hardware control and data analysis}

The iDirac is controlled using a dual Arduino system: an Arduino Micro board controls the gas flow components of the instrument, whilst the main instrument control is achieved with an Arduino Mega board. These two units communicate with all of the sensors inside the instrument and read their outputs. A Raspberry Pi computer acts as the interface between the user and the Arduino boards. A Python script is run on the Raspberry $\mathrm{Pi}$, allowing the user to configure the instrument with the desired parameters and read the sensor output from that of the Arduino. The Raspberry Pi desktop can be accessed remotely via an ad hoc network, allowing connection with a variety of interfaces. This control system allows many of the parameters described above (e.g. sample volume and time spent in each column) to be changed. 


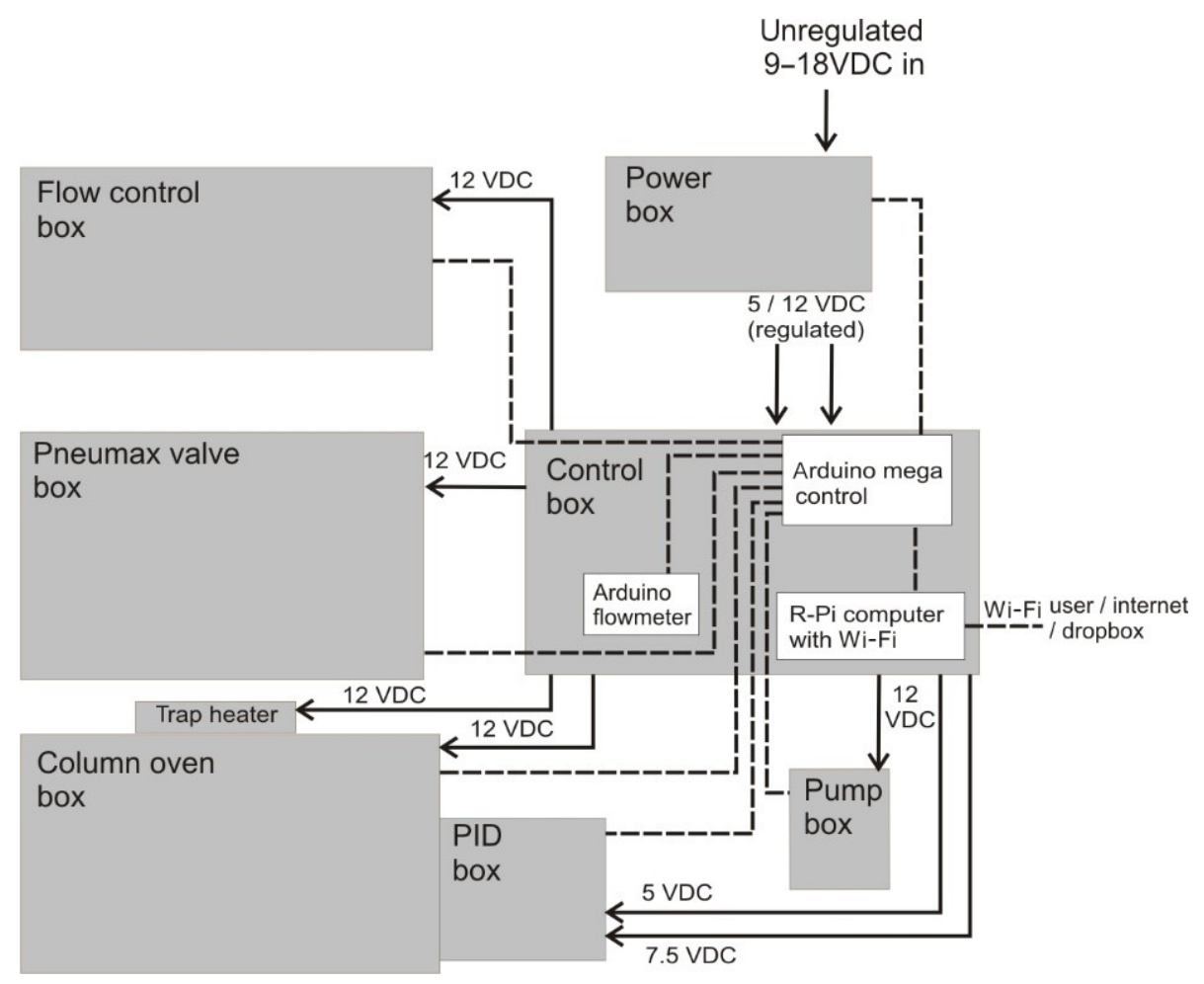

Figure 4. Schematic of Arduino Mega connections.

\subsection{Arduino control of internal electronics}

The instrument is controlled primarily using an Arduino Mega 2560 board (Arduino Mega 2560, Arduino). This microcontroller has a number of analogue and digital ports and runs Arduino code ( $\mathrm{C}$ and $\mathrm{C}++$ commands) to control these ports. An SD breakout board is used (microSD card breakout board, Adafruit) to facilitate the use of an SD card to store data in, while a real-time clock (RTC) board is used (real time clock, ChronoDot ultra-precise, Adafruit) for time-keeping. Figure 4 illustrates the various connections on the Arduino Mega.

An Arduino Micro board (Arduino Micro, Arduino) specifically reads the altimeter pressure sensor (located in the PID box) and the flowmeter, and sends these readings to the Arduino Mega via a serial port. The use of the Arduino Micro is justified as it simplifies the code on the Arduino Mega, particularly as the flowmeter requires the use of a shifter to convert the RS232 serial signal and several subsequent mathematical manipulations. The Arduino boards do not have a shutdown procedure and can simply be unplugged.

\subsection{Description of Raspberry Pi user interface}

The iDirac uses a Raspberry Pi (Raspberry Pi Model B V1.1, Raspberry Pi) as a user interface, allowing the instrument to be controlled from a familiar desktop environment. The Raspberry Pi uses a Wi-Fi dongle to set up its own ad hoc network, which can be connected to by laptops and mobile phones in a fashion similar to a standard Wi-Fi network. Once connected to the network, a graphical desktop sharing system such as VNC viewer (VNC Viewer, RealVNC) allows the user to navigate the Raspberry Pi desktop and manipulate the instrument.

Upon opening the Raspberry Pi desktop a purpose-written Python script is launched automatically. A terminal window is opened displaying the serial output from the Arduino Mega and transmitting data to the Arduino Mega via a serial port connection. The latest version of this Python script is freely available (https://github.com/cgb36/iDirac-scripts, last access: 5 January 2020). The Python script decodes incoming serial bytes from the Arduino Mega and displays them in a user-friendly command line window. It is also possible to restart and shutdown the instrument from the Raspberry Pi desktop. The Raspberry Pi requires a shutdown procedure, which can be done either physically with a switch on the side of the control box or from the virtual desktop environment.

\subsection{Processing of chromatograms}

To process numerous chromatograms in an automated fashion, a script was created that uses calibration runs to accurately identify isoprene peaks in the sample runs and convert their integrated peak areas into mixing ratios. This script is written in Mathematica (v11.1.1). Figure 5 shows a flow dia- 
gram for the main algorithms of the script. Firstly the data are read in, making sure that all the files are the correct size and do not contain any erroneous runs (e.g. corrupted or truncated files) that may jeopardise the running of the script. Each chromatogram file has an index field, either S, X, C or $\mathrm{B}$ which indicate if the chromatogram is a Sample 1, Sample 2 , calibration or blank chromatogram respectively.

The calibration data are processed first. This involves selecting all calibration chromatograms (those with index "C") and plotting them for visual inspection. From the plot of all calibration chromatograms, the user specifies the regions that are used to fit to the isoprene peak and the baseline. A third-degree polynomial is fitted to the baseline over the user-specified baseline intervals. A Gaussian curve is then fitted to the baseline-subtracted chromatogram over the userspecified peak interval. The peak height, width and position (equivalent to elution time) of the fitted Gaussian, as well as the error in the fit (root-mean-square error, RMSE), are logged. The elution time of the peak is retained in an interpolated function over time. This function is then used to locate the isoprene peak in the sample runs between two calibration runs. The blank runs (with index "B") are included in this routine as they effectively represent calibrations with zero isoprene concentration. Subsequently, the peak area is plotted against the number of calibrant moles to obtain a response curve. The number of calibrant moles, $n_{\text {cal }}$, is defined as

$n_{\mathrm{cal}}=\left(V_{\mathrm{cal}} / V_{\mathrm{mol}}\right) \cdot \chi_{\mathrm{cal}}$

where $V_{\text {cal }}$ is the sampled volume of the standard during the run, $V_{\mathrm{mol}}$ is the molar volume of an ideal gas and $\chi_{\mathrm{cal}}$ is the isoprene amount fraction in the gas standard. A straight line is then fitted to these data. Calibration procedures are described in depth in Sect. 4.1.

The sample chromatograms are then selected as either Sample 1 (runs with index "S"), or Sample 2 (runs with index "X") and, as with the calibration runs, they are plotted to visually inspect the data. Following this, we interpolate the retention times from adjacent calibration runs to the time of each sample runs, thus ensuring that the isoprene peak is identified correctly. This effectively takes variation in elution time caused by varying oven temperatures into account. A baseline is fitted to the sample chromatograms in a similar fashion to those fitted to the calibration chromatograms. Then a Gaussian function, constrained by certain boundaries (e.g. peak width within the average calibration peak width $\pm 1 \mathrm{SD}$ and retention time within $\pm 4 \mathrm{~s}$ of the interpolated retention time), is fitted to the section of the chromatogram indicated by the interpolated calibration retention times. Using the sample peak area $\left(A_{\text {sam }}\right)$, the sample volume $\left(V_{\text {sam }}\right)$, and the intercept $(c)$ and gradient $(m)$ of the calibration curve, the isoprene mixing ratio in the sample, $\chi_{\mathrm{sam}}$, is calculated using Eq. (2):

$\chi_{\mathrm{sam}}=\left(A_{\mathrm{sam}}-c\right) / m \cdot\left(V_{\mathrm{mol}} / V_{\mathrm{sam}}\right)$.
When there are insufficient calibration chromatograms to determine the isoprene peak retention time (e.g. less than four calibration runs in a day), it can be estimated using the column temperatures from the nearest calibration runs. If the spacing between calibration points is too great or the calibration is carried out separately to the sampling, the interpolated calibration retention time values may not span the region where the isoprene peak resides. In this case the column temperature and retention time of the most recent calibration chromatograms are used to define a linear relationship. It is then possible to derive the isoprene retention time from the column temperature of the sample chromatogram.

\section{Instrument performance}

\subsection{Calibration of output chromatograms}

The PID response to isoprene is calibrated using a primary gas standard supplied by the National Physical Laboratory (NPL), certified as containing $5.01 \pm 0.25 \mathrm{nmol} \mathrm{mol}^{-1}$ (or ppb) isoprene in a nitrogen matrix (uncertainty provided at the $k=2$ level). The gas mixture is stored in a $10 \mathrm{~L} \mathrm{Ex}-$ peris cylinder (Air Products); this type of cylinder has been demonstrated to provide maximum stability (up to 2 years) for VOC mixtures over time (Allen et al., 2018; Rhoderick et al., 2019). The primary standard is only used for calibration in the laboratory; for field deployments, a smaller secondary gas standard is used instead. This is prepared manometrically by diluting a higher concentration parent mixture (100 nmol mol ${ }^{-1}$ isoprene in nitrogen, BOC) to approximately $10 \mathrm{nmol} \mathrm{mol}^{-1}$ with high-purity nitrogen (BIP+, Air Products). This secondary gas standard is prepared in a $500 \mathrm{~mL}$ SilcoNert-treated stainless steel cylinder (Sulfinert sample cylinder, TPED, 1/4", Thames Restek). This type of treated cylinder exhibits very good long-term stability for a number of VOCs (Allen et al., 2018; Rhoderick et al., 2019). The exact isoprene amount fraction in the secondary standard is determined by validating it against the NPL primary standard. This way, the measurements from the iDirac are traceable to accurate primary standards. We routinely measure the secondary standards against the primary standard before and after field deployments to account for any degradation over time. However we have found no statistically significant degradation over the time span of field deployments (up to 5 months).

Frequent calibration is needed not only to convert chromatogram peaks into mixing ratios, but also to monitor long-term trends in the detection system, including detector drift and decreasing performance of the adsorbent trap. Any changes in isoprene elution time, which may be caused by changes in oven temperature, can affect the correct peak assignment in chromatograms with multiple peaks. These effects can be easily addressed if frequent calibration chro- 


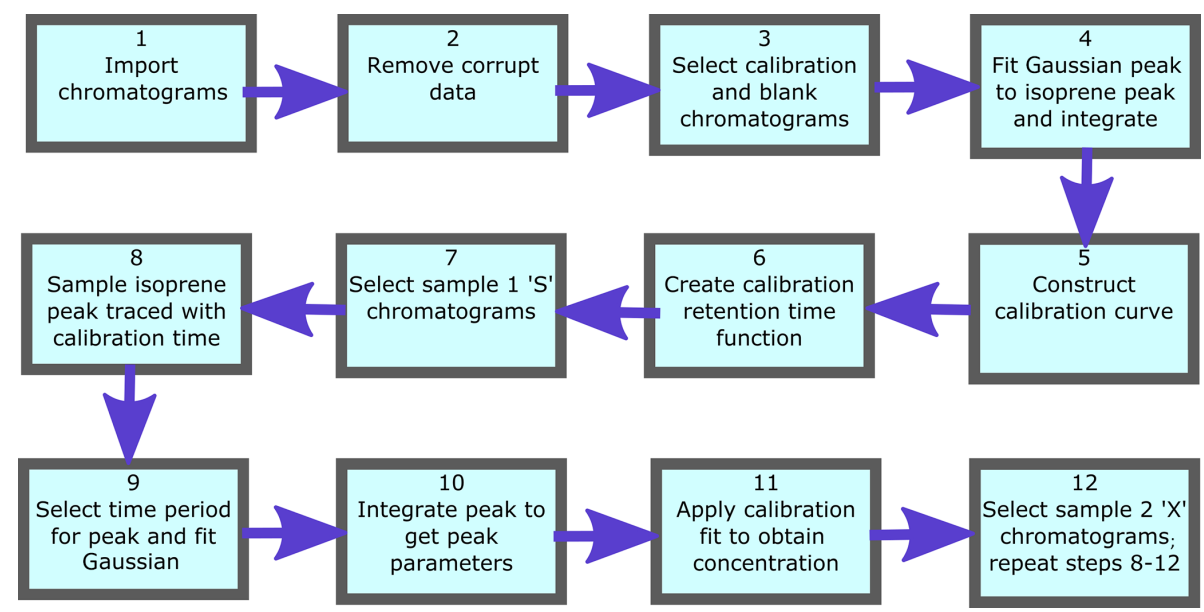

Figure 5. Analysis script flow diagram.

matograms (which only have, by definition, one peak) are available.

Calibration frequency is specified by the user in the instrument set-up by selecting the number of samples to run between calibrations. For example, a calibration frequency of "4" would correspond to a run of four sample chromatograms, followed by a calibration run. It is essential to perform a calibration run periodically to ensure that the position of the isoprene peak can be traced. Typically, a calibration run is performed every 35 sample runs. As the mean duration of a $150 \mathrm{~mL}$ sample run is approximately $9 \mathrm{~min}$ (consisting of $7.5 \mathrm{~min}$ of sampling and $1.5 \mathrm{~min}$ of chromatographic run), a calibration run is performed approximately every $5.25 \mathrm{~h}$.

The calibration cycle is programmed to be preceded and followed by a blank run, in which the system samples from the high-purity nitrogen supply from valve 4 . This allows any residual isoprene in the trap to be desorbed before and after calibration, and also allows the efficiency of desorption over time to be monitored.

A calibration curve is obtained by varying the volume sampled in each calibration run. When configuring the instrument, the user specifies a calibration volume in millilitres, which is sampled every other calibration run. For the remaining calibration runs, the instrument is programmed to sample a volume picked randomly from five possibilities: the user-specified calibration volume, the user-specified calibration volume multiplied by 2 or 4 , and the user-specified calibration volume divided by 2 or 4 . For instance, for a run configured with a calibration volume of $12 \mathrm{~mL}$, half the calibration runs would be of $12 \mathrm{~mL}$ samples and half would be a random mixture of 3, 6, 12, 24 and $48 \mathrm{~mL}$ samples. A typical time sequence of isoprene peak areas from different calibration volumes is shown in Fig. 6. A calibration curve is then obtained by plotting these peak areas against the number of calibrant moles (as defined in Eq. 1). The zero moles point is obtained from the blank runs. A straight line is fitted to the calibration data. A typical calibration plot is shown in Fig. 7. The straight line fit allows the determination of the fractional isoprene amount in the samples via Eq. (2) by extrapolation or interpolation, provided the sample volume and peak area are known. Typically, data are analysed in weekly segments, so that a calibration curve is obtained for each week.

The error in the sampled volumes is dominated by the dead volume in the gas lines before the trap (approximately $1.6 \mathrm{~mL}$ ) combined with the uncertainty in the measurement of flow rates $(1 \%)$ and sampling times $(0.05 \%)$. The overall uncertainty in the volumes is estimated as $50 \%$ for $3 \mathrm{~mL}$, $13 \%$ for $12 \mathrm{~mL}, 3 \%$ for $48 \mathrm{~mL}$ and $1 \%$ for $200 \mathrm{~mL}$.

As interpolation carries lower uncertainty than extrapolation, it is important to choose an appropriate value for the user-specified calibration volume, so that the points in the calibration curve span the entire range of the sample runs (as is the case in Fig. 6). Typically, $12 \mathrm{~mL}$ is suitable in an environment with relatively low $(<1 \mathrm{ppb})$ isoprene concentrations (e.g. remote oceans), whereas a higher value $(20 \mathrm{~mL})$ is more appropriate when measuring in areas such as tropical forests.

\subsection{Precision and accuracy of iDirac data}

\section{Precision}

The precision of the instrument was determined as the relative standard deviation in isoprene peak area from calibration chromatograms with the same user-specified volume (typically, more than $50 \%$ of the total calibration runs in any given measurement sequence, as detailed in Sect. 4.1) and from the same calibration cylinder. For instance, in the calibration sequence shown in Fig. 7, this corresponds to the runs of $12 \mathrm{~mL}$ samples. Following analysis of the scatter of these data points, the instrument precision is determined to be $\pm 10.4 \%$ in the field (compared with $<5 \%$ in the labo- 


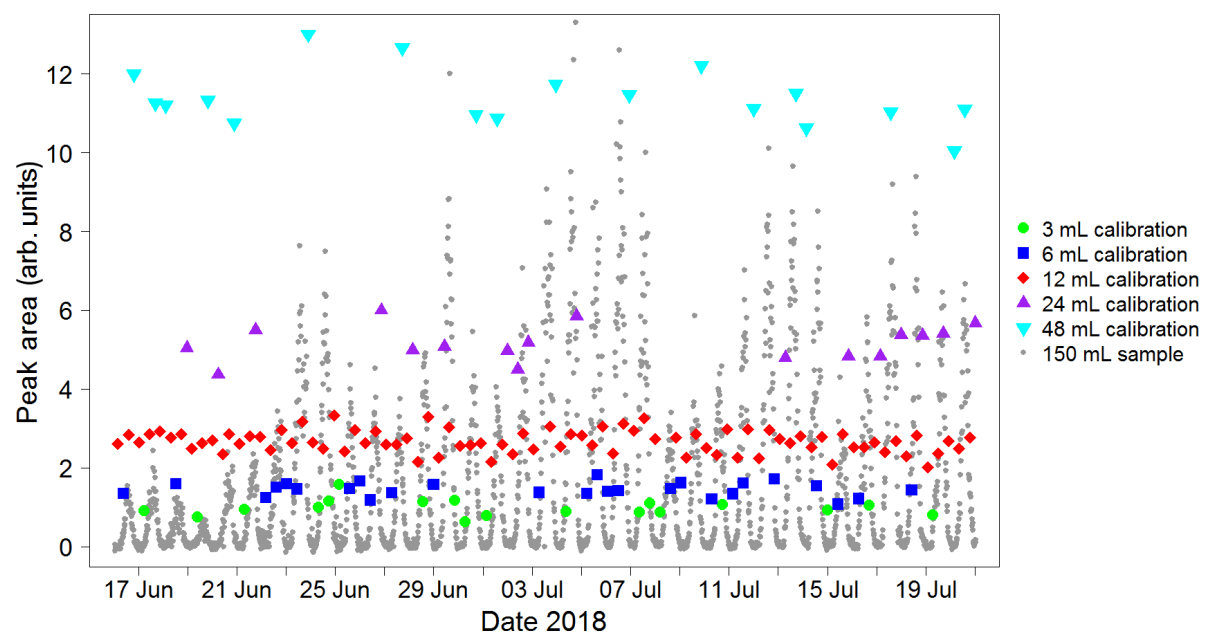

Figure 6. Typical sequence of isoprene peak areas for runs with varying calibration volumes. These, once split into weekly segments, are used to produce a calibration curve (see Fig. 7). The calibration runs with the standard user-specified sampled volume (red data points) are used to calculate the instrument precision on a weekly basis (see Sect. 4.2). Peak areas from sample runs (grey data points) are also shown to illustrate how the calibration peak areas span the entire range of sample values, minimising the need for extrapolation. This plot was produced using data from the Wytham Woods field campaign (see Sect. 5.2).

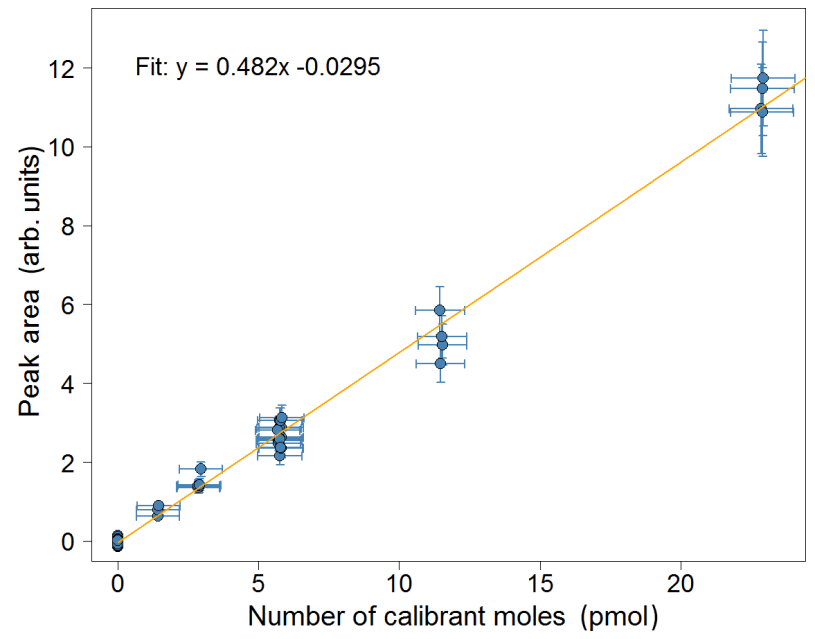

Figure 7. Calibration plot for isoprene for the week of 28 July 2018 from the Wytham Woods field campaign. Error bars in the area correspond to the precision of the measurement $( \pm 10.4 \%)$. Error bars in the calibrant moles are estimated from the uncertainties in the secondary standard used and in the volume of gas sampled.

ratory). This procedure is carried out for each weekly segment of the data so that the measurement precision can be routinely monitored over time which is especially useful for long deployments.

\section{Accuracy}

One of the main components of the accuracy of the instrument is the uncertainty in the isoprene amount fraction in the NPL standard, and how this is propagated to the isoprene amount fraction in the secondary gas standard used in the field. Therefore, it is essential that the concentration of the secondary calibration cylinder is determined as accurately as possible by comparing it to the NPL primary standard. This is carried out in the laboratory, typically before and after each field deployment.

An example of this concentration determination is shown in Fig. 8. XLGENLINE, a freely available generalised leastsquares (GLS) software package for low-degree polynomial fitting (Smith, 2010), is used to estimate the uncertainty in the isoprene amount fraction in the secondary calibration cylinder. This is carried out in two steps. First the calibration data (i.e. the peak areas and sampled volumes from the NPL primary standard) are run through XLGENLINE to produce a calibration line with an associated uncertainty envelope. In the second step, this calibration curve is used to convert the peak areas from the secondary standard (i.e. the "unknown") into concentrations and their associated uncertainties. For secondary calibration cylinders, this is estimated as $\sim 3.5 \%$ $( \pm 1 \mathrm{SD})$. A similar procedure is applied to field data to estimate the uncertainty in the ambient isoprene concentrations (now using the secondary standard for the calibration). This is estimated as $\sim 10 \%-12.5 \%( \pm 1 \mathrm{SD})$.

Co-elution of interfering species can also affect accuracy. Tests targeting specific potential interferents are described in Sect. 5.1 and show that these species do not overlap with the isoprene peak in the chromatograms. However co-elution 


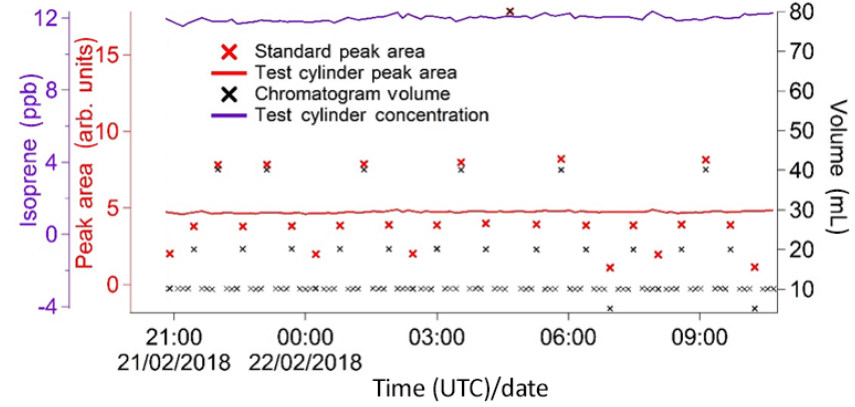

Figure 8. Summary plot of a concentration determination experiment. The primary reference gas mixture is used as the standard in the calibration runs, and the secondary gas mixture under test is used as the sample.

with unknown (or not tested for) species, albeit unlikely, can never be fully ruled out. If these species have longer lifetimes than isoprene, the observed night-time abundances attributed to isoprene can be used as the upper limit of potential interference of unknown co-eluters (assuming they are trapped with the same efficiency and have the same PID response as isoprene). The isoprene night-time mixing ratio is $50 \mathrm{ppt}$ for the data shown in both Figs. 14 and 15. Therefore, we estimate the instrument accuracy for field data as the combination of the propagated uncertainty from the standard $(10 \%-12.5 \%)$ and the potential co-elution of long-lived species $(50 \mathrm{ppt})$. This correspond to an overall accuracy of $\pm 1.2 \mathrm{ppb}$ for a $10 \mathrm{ppb}$ isoprene sample, $\pm 0.13 \mathrm{ppb}$ for a $1 \mathrm{ppb}$ isoprene sample and $\pm 51 \mathrm{ppt}$ for a $100 \mathrm{ppt}$ isoprene sample.

Deviations of peak shape from a simple Gaussian function also impact accuracy by introducing a bias in the reported peak areas. However this is limited to high volume, high concentration samples and can add $\sim 2 \%$ to the overall accuracy budget.

\subsection{Sensitivity of the iDirac to isoprene}

The instrument's sensitivity can be adjusted by changing the volume of the sample being analysed. For high concentrations (e.g. strong leaf emissions) a smaller volume should be used to avoid nonideal behaviour of the adsorbent, as described by Peters and Bakkeren (1994). The instrument has an effective upper volume limit of $250 \mathrm{~mL}$ (see Sect. 5.1) and a lower limit of $3 \mathrm{~mL}$. The volume integration becomes unreliable below $3 \mathrm{~mL}$ due to the additional uncertainty brought about by the dead volume before the trap (approximately $1.6 \mathrm{~mL}$ ). Conversely, when ambient levels of isoprene are low $(<500 \mathrm{ppt})$, large sample volumes $(200 \mathrm{~mL})$ should be used. Sample volumes lower than or equal to $200 \mathrm{~mL}$ are used in order not to exceed the trap breakthrough volume (see Sect. 5.1).

The limit of detection is determined for a specific set of runs by allowing a signal-to-noise ratio $(S / N)$ of 3 . The blank runs are used to calculate the noise, which is defined

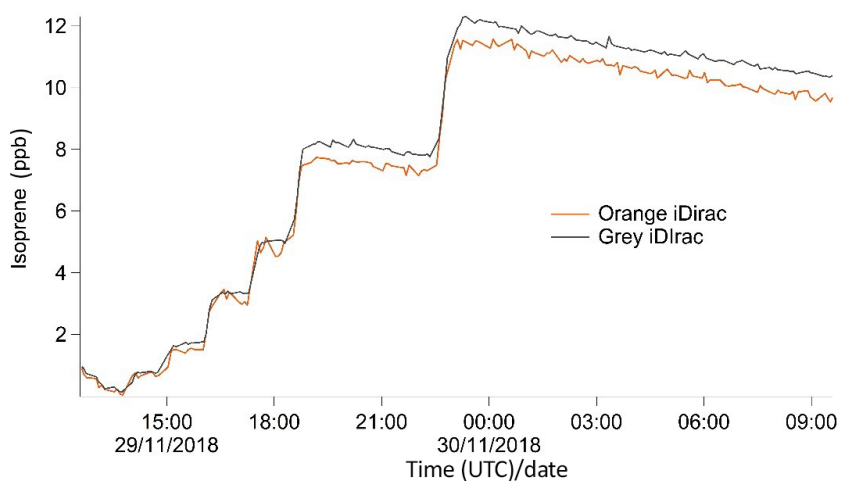

Figure 9. Time series plot showing isoprene mixing ratios from the grey and orange iDirac instruments.

as the standard deviation in the PID signal in a section of the blank chromatogram corresponding to the isoprene elution time. The instrument response factor is calculated from the isoprene peak height in the calibration runs and the isoprene amount fraction in the standard. This allows the calculation of the minimum concentration needed to give rise to a signal that would return a $S / N$ of 3 . This is identified as the limit of detection and is monitored routinely during field deployments and laboratory tests. The limit of detection for two versions of the iDirac, the grey and the orange instruments (see Sect. 5.1 for details), during their deployment in the Wytham Woods field campaign (See Sect. 5.2) were 108 and $38.1 \mathrm{ppt}$ respectively. These are higher than the limit of detection determined in the laboratory (46 and $19 \mathrm{ppt}$ respectively). The difference between field and laboratory sensitivity is due to greater noise in the field measurements, as a result of less controlled environmental conditions. The difference in the limit of detection between the two instruments is attributed to differences in instrumental noise (the noise in the orange iDirac is $10 \%-20 \%$ greater than that from the grey iDirac), different responses of the PIDs to isoprene, and using traps at different stages of their life cycle (refer to Sect. 5.3.2 and Fig. 16).

\section{Tests in the laboratory and field deployments}

The iDirac has been tested in a series of laboratory evaluations, during a deployment at a field station in a tropical forest in Sabah, Malaysia, and in a research forest in Wytham Woods, UK.

\subsection{Laboratory tests}

\section{Intercomparison of two versions of the iDirac}

Two iDirac instruments (orange and grey) were compared against one another, with the two instruments sampling from a chamber containing a controlled isoprene concentration that was varied over time. The orange and grey iDirac in- 


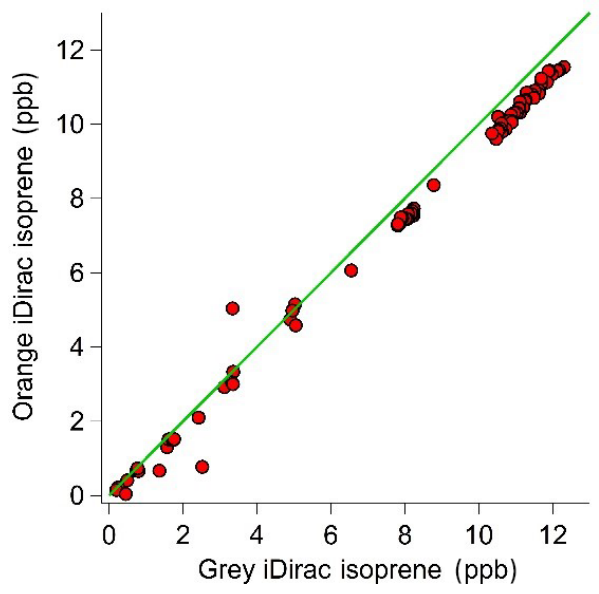

Figure 10. Scatter plot with the $1: 1$ line showing the $15 \mathrm{~min}$ average values for the grey and orange iDirac instruments.

struments both had inlets inside the chamber with identical filters (polyethersulfone, $0.45 \mu \mathrm{m}$ pore-size) and the same $1.5 \mathrm{~m}$ length of PTFE $1 / 16^{\prime \prime}$ tubing, and they were placed as close to one another as possible. The gas within the chamber was well mixed by two large fans. Gas from a $700 \mathrm{ppb}$ isoprene $( \pm 5 \%)$ in a nitrogen balance mixture (BOC) was flow-controlled into the chamber at $80 \mathrm{~mL} \mathrm{~min}^{-1}$ for different time periods to change the concentration. The chamber was not flushed, and the only exchange out of the chamber was slight seepage through several small holes around the inlets. The concentration was varied stepwise from 0 to $12 \mathrm{ppb}$. The instruments were calibrated using the same calibration standard ( $8.3 \pm 0.6 \mathrm{ppb}$ isoprene in nitrogen), which was connected to both instruments via a tee-piece.

The results from this experiment are shown in Fig. 9. The orange iDirac under-reads by $6.6 \%$ relative to the grey iDirac, and this is particularly evident at high concentrations (> $8 \mathrm{ppb}$ ). Figure 10 shows these data as a scatter plot of the $15 \mathrm{~min}$ average values from either instrument, and, again, it can be seen that the orange iDirac under-reads slightly. This under-reading is partly attributed to the systematic underestimation of the peak areas from the orange runs due to peak tailing. Integration of a subset of chromatograms using an exponentially modified Gaussian function showed that a simple Gaussian fit underestimates peak areas from the orange instrument by up to $2 \%$. No significant degree of tailing was observed in the runs from the grey instrument. Despite this slight discrepancy between the output isoprene concentration from the two instruments, it should be noted that the two iDirac instruments perform within their specified accuracies (see Sect. 4.2).

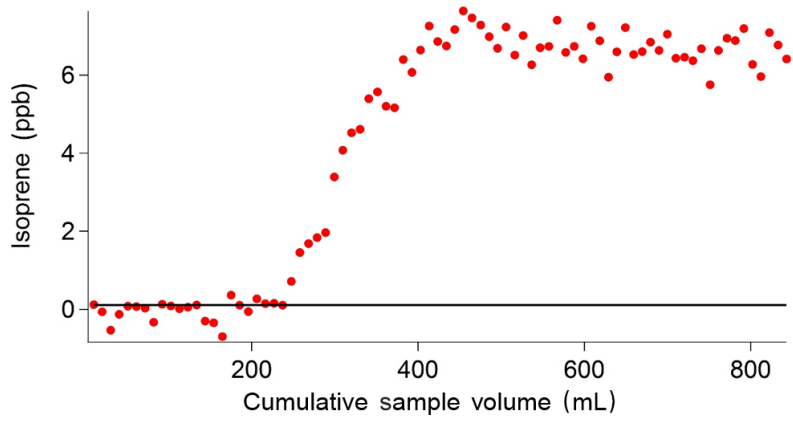

Figure 11. Results of the breakthrough volume tests. Each data point is an individual sample run of $10 \mathrm{~mL}$. A solid black line indicates a threshold (set at a LOD of $0.108 \mathrm{ppb}$ ), above which the breakthrough volume is exceeded.

\section{Breakthrough tests}

The breakthrough volume for the adsorbent traps used in the iDirac was determined. This is a test that evaluates the volume of gas that causes isoprene to pass through the trap in a single sample run, and is typically independent of the analyte concentration (Peters and Bakkeren, 1994). This test is performed by placing an additional adsorbent trap in the instrument upstream of the main trap, at the exit of valves 1-4 from the valve box. Each run sampled $10 \mathrm{~mL}$ of a mixture of $5 \mathrm{ppb}$ isoprene and $5 \mathrm{ppb} \alpha$-pinene in a nitrogen balance. When the breakthrough volume of the additional trap is exceeded, isoprene effectively 'breaks through' from the additional trap onto the main trap, so that it is injected onto the dual-column system and a peak is observed in the chromatograms. The sum of all the volumes of the runs in which isoprene was not observed (i.e. pre-breakthrough) gives the breakthrough volume. This value effectively acts as an upper limit of the volume of gas that the instrument can sample. Figure 11 shows a typical example of such test, in which a breakthrough volume of $250 \mathrm{~mL}$ was determined. Thus, the instrument is set to sample volumes up to $200 \mathrm{~mL}$ so that the breakthrough volume is never exceeded.

\section{Co-elution of interfering species}

The PID used in the iDirac is sensitive to all molecules with ionisation energies less than or equal to $10.6 \mathrm{eV}$, which includes the vast majority of biogenic and anthropogenic VOCs with the exclusion of ethane, acetylene, propane, methanol, formaldehyde and a number of halogenated hydrocarbons. Therefore, it is possible that species co-eluting at the same time as isoprene might be detected and erroneously identified as isoprene, thus leading to reporting of spurious concentrations. The stationary phase in the main column is selected to achieve good separation of isoprene from VOCs of similar polarity and boiling point. This is tested in a series of coelution experiments, in which the elution time of a number of potentially interfering species was determined and their sep- 


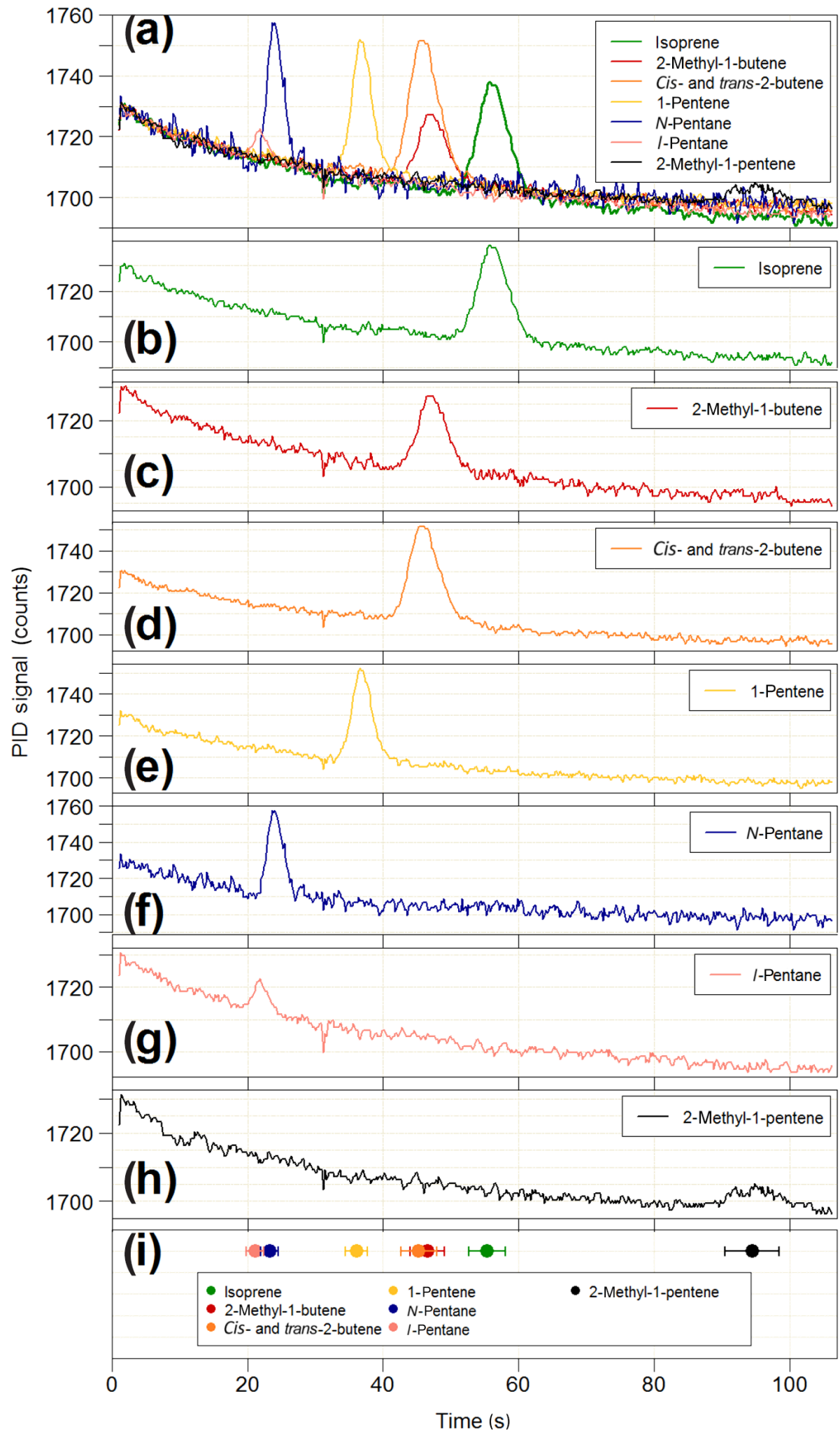

Figure 12. Results of the co-elution tests on the iDirac. (a) Overlaid chromatograms of isoprene (green line) and six potential interfering species: 2-methyl-1-butene (red line), cis- and trans-2-butene (orange line), 1-pentene (yellow line), $n$-pentane (blue line), $i$-pentane (pink line) and 2-methyl-1-pentene (black line). The chromatograms of each individual species are shown in panels (b-h). The co-elution tests are summarised in panel (h), where the elution time of each species (filled circles) is plotted along with its peak width (FWHM) to assess peak separation. 


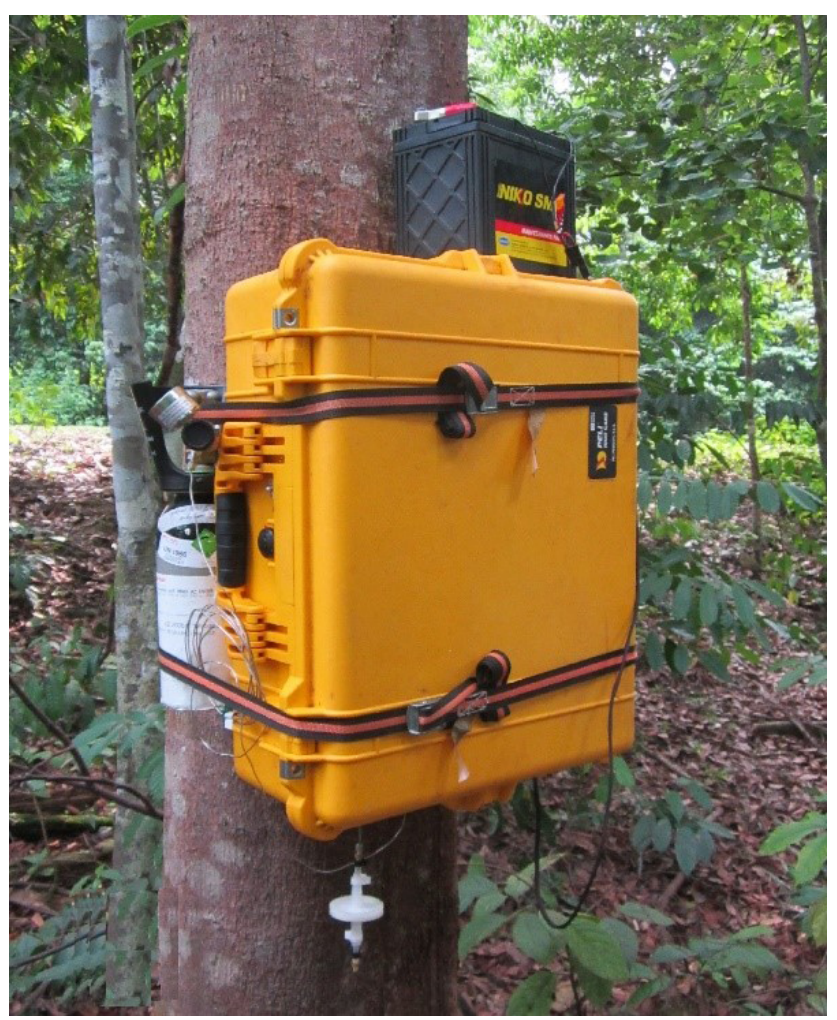

Figure 13. iDirac deployed in a tropical forest environment.

aration from isoprene assessed. The VOCs under test were chosen based on the column specifications reported by the manufacturer, which identified $i$ - and $n$-pentane, 1-pentene, cis- and trans-2-butene, 2-methyl-1-butene and 2-methyl-1pentene as potentially co-eluting with isoprene. Gas samples containing $10-20 \mathrm{ppb}$ of each interfering VOC are prepared in $3 \mathrm{~L}$ Tedlar bags by two-step dilutions from the "pure" substance (Sigma Aldrich, purity typically $>98 \%$ ) using grade 5.0 nitrogen (purity $>99.999 \%$ ). For each interfering species, the iDirac alternated between sampling from one of the Tedlar bags and sampling from a gas cylinder containing only isoprene in nitrogen. The results of these measurements are summarised in Fig. 12. Figure 12a illustrates overlaid chromatograms for each species, and the individual chromatograms are shown in Fig. 12b-h. Figure 12i summarises the different elution times taking the width of each peak (full-width at half maximum - FWHM) into account to better assess separation. The isoprene peak is well separated from all interfering VOCs, whereas we observe poor separation between cis- and trans-2-butene (which are not separated at all and appear as a single peak in Fig. 12d) and 2methyl-1-butene, as well as between $i$ - and $n$-pentane. Similar tests were carried out for acetone and ethanol, and we found that they eluted outside of the chromatographic window considered here. These results lend confidence to the unequivocal assignment of the isoprene peak in each chromatogram. Work is ongoing to determine the elution time of

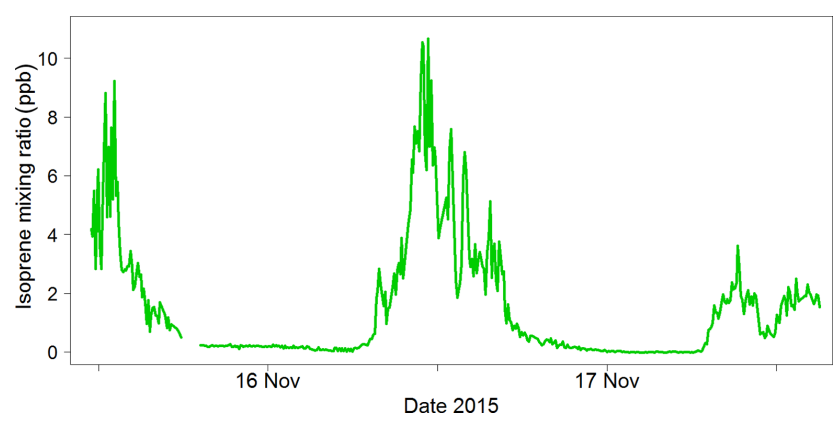

Figure 14. Time series for isoprene at a secondary forest site in Sabah (Malaysian Borneo) in 2015.

a wider range of compounds, including oxygenated products from the oxidation of isoprene.

Co-elution and multiple peaks appearing in a chromatogram are also addressed in the Mathematica script described in Sect. 3.3. To ensure that the isoprene peak is correctly assigned, the script looks for a peak in a relatively narrow region of the chromatogram, which is based on an interpolation of the elution time from the two nearest calibration runs. This algorithm has relatively low tolerance, so that peaks that are more than $4 \mathrm{~s}$ away from the predicted isoprene elution time are not considered.

We observe a consistent discrepancy in the isoprene elution time between the calibration and sample runs. The elution time of isoprene is typically $1.7 \mathrm{~s}$ greater in a sample run than in a calibration run. This is an artefact of the trap adsorption process and the resulting tailing of the peak. For large volumes and low concentrations (e.g. a $150 \mathrm{~mL}$ field sample at $0.5 \mathrm{ppb}$ ), the isoprene band in the adsorbent trap is very broad and resides in the trap for a longer time, so it tails very strongly. For a high-concentration low-volume sample (e.g. a $12 \mathrm{~mL}$ calibration run at $10 \mathrm{ppb}$ ), the isoprene band in the trap adsorbent is very sharp, it desorbs quickly and, hence, it tails less. This difference in elution times is much smaller than the distance to the nearest interfering species (2-methyl-1-pentene, which elutes $\sim 7 \mathrm{~s}$ before isoprene).

The peak width and the RMSE from the Gaussian fit, retrieved from the fitting routine described in Sect. 3.3, can also be used to evaluate the presence of co-eluting species. An additional peak overlapping to some degree with the target isoprene peak in a sample run would cause a change in the peak shape. This would result in values for the fitted peak width and RMSE that are different from those from the calibration runs. For this reason, we use the width and RMSE from the calibration runs to define a range of acceptable peak widths and RMSE values (equal to the mean value $\pm 1 S D$ ). Any peaks from sample runs exceeding this range are flagged for further analysis. 


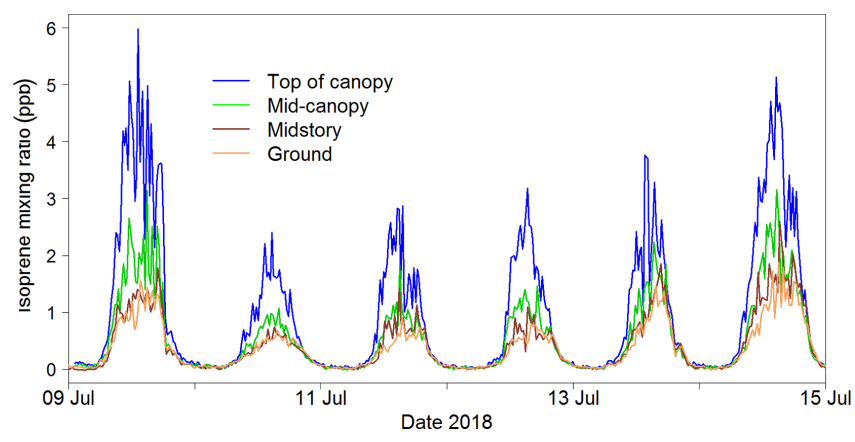

Figure 15. Portion of the isoprene mixing ratio time series measured during the Wytham Woods field campaign (UK) at four heights within a forest canopy in the summer of 2018.

\section{Long-term tests}

The performance of the instrument in the field for long periods of time has been assessed during several deployments. These are described in detail in Sect. 5.2

\subsection{Deployment of the iDirac in Sabah, 2015}

Following laboratory development and testing, the iDirac had its first field deployment at the Bukit Atur Global Atmosphere Watch (GAW) station in the Danum Valley Conservation Area in Sabah (Malaysian Borneo) as part of the "Biodiversity and land-use impacts on tropical ecosystem function" (BALI) plant traits campaign. This campaign ran from May to December 2015. The instrument was principally used to carry out individual leaf measurements in the field. The results from the individual leaf measurements are being written up for publication elsewhere.

The other type of measurements taken in Sabah during this timeframe were longer duration runs, in which the instrument took autonomous measurements of ambient air at the field site continuously. These measurements consisted of attaching the iDirac to a tree at a height of approximately $1 \mathrm{~m}$, with a battery and a $1.2 \mathrm{~L} \mathrm{~N}_{2}$ cylinder attached to it, and running repeat samples until either the battery ran flat or the gas supply was exhausted. The aim of these measurements was to obtain an isoprene diurnal profile and observe how this varied with different types of forest. These tests also allowed us to test the feasibility of leaving the instrument running for long periods of time. A picture of the iDirac measuring ambient air in the rainforest in Borneo is shown in Fig. 13.

The ambient air measurements demonstrated that the instrument could easily measure the changes in isoprene concentration in the ambient air and that the inlet drying system could cope with the high humidity of the rainforest. An example from a secondary forest site is shown in Fig. 14. This was the first deployment for the iDirac, and it proved to be a success with respect to taking reliable measurements. It also highlighted areas for instrument development (e.g. cal- ibration routine) and several issues with instrument function (e.g. warm-up time) that have been addressed in subsequent versions.

\subsection{Deployment of the iDirac during the Wytham Woods field campaign (University of Oxford)}

\subsubsection{Experiment description}

The instrument was deployed in Wytham Woods (Oxfordshire, UK), a temperate mixed deciduous forest owned and managed by the University of Oxford. A large fraction of trees at this site are pedunculate oaks (Quercus robur), which are known strong isoprene emitters (Lehning et al., 1999). One iDirac was deployed on the canopy walkway facility, a platform $\sim 15 \mathrm{~m}$ above ground resting on a scaffolding support that allowed access to crown-level measurements, while another iDirac was installed at ground level. As each instrument has two inlets, this allowed sampling at four heights across the canopy with a view to investigating the isoprene concentration gradient within the canopy. Both iDirac instruments were run off-grid, powered only by solar-powered batteries. The experiment and results are described in detail by Ferracci et al. (2020a) and Otu-Larbi et al. (2019). Data were collected from May to October 2018; here, the performance of the instruments is assessed for more than 5 months of continuous use in a forest environment.

\subsubsection{Results and discussion}

The iDirac captured isoprene concentrations from 25 May to 29 October 2018. Gaps in the data were generally due to power issues arising from insufficient solar charging of the batteries. A section of the isoprene time series is shown in Fig. 15. The diurnal pattern of isoprene is clearly visible, and the vertical concentration gradient is also apparent.

The iDirac proved capable of measuring isoprene abundances continuously through the day, spanning from concentrations as high as $8 \mathrm{ppb}$ in the height of the summer to effectively zero at night-time.

The lifetime of the absorbent trap can be assessed by examining the calibration curves over time. The dataset is analysed in weekly segments, with a calibration curve constructed for each week. This allows for the calibrated data to account for any drift in sensitivity. The calibration plots exhibit a clear drift as time progresses, as shown in Fig. 16, with calibration chromatograms later in the time series showing a lower peak area for the same concentration. Once the trap is replaced, higher sensitivity is recovered (shown as the green dashed line in Fig. 16a and the green square in Fig. 16b).

This drift is attributed to the gradual degradation of the trap as a result of repeated absorption/desorption cycles, with exposure to high concentrations of VOCs and oxygen. As each week of data represents approximately 1000 absorption/desorption cycles, it is likely that the absorbent in the 

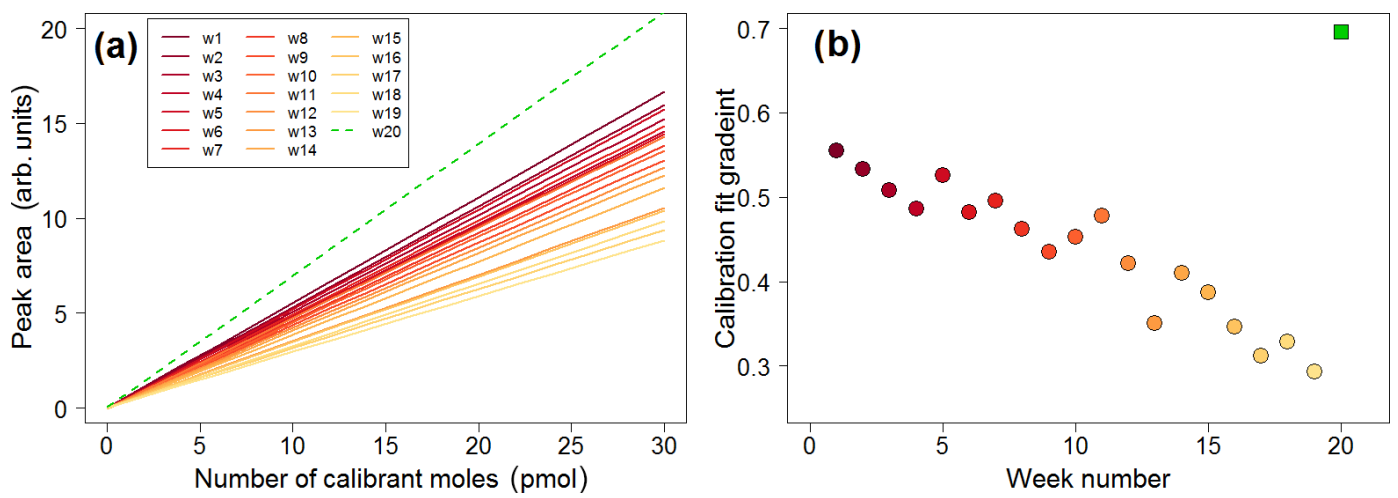

Figure 16. (a) Calibration lines plotted in weekly intervals, showing decreasing sensitivity over time (solid lines). The green dashed line is the calibration plot obtained once the trap was replaced. (b) Time series of the gradients of the calibration plots showing decreasing sensitivity (filled circles). The green square represents the calibration plot gradient obtained after replacing the trap.

trap is degraded over time and eventually needs to be replaced.

Decreasing sensitivity would obviously affect the limit of detection of the instrument. During a particularly long deployment such as that in the Wytham Woods field campaign, it is important to monitor the sensitivity by means of plots such as that in Fig. 16 in order to better establish when the trap needs to be replaced.

\section{Conclusions and future work}

We described the development and subsequent deployment of the iDirac, a novel autonomous GC-PID for isoprene measurements in remote locations. The instrument preconcentrates ambient VOCs on an adsorbent trap and then separates them in a dual-column system kept in an isothermal oven before detection by a photoionisation detector, achieving a limit of detection for isoprene down to $38 \mathrm{ppt}$. The rugged design and modular construction make the instrument easily customisable, while the open-source software control results in a straightforward instrument configuration. Designed for field deployments in remote environments with limited power supply, the iDirac weights $10 \mathrm{~kg}$ (excluding the gas supply), consumes minimum power and gas, can be run autonomously for months with little maintenance (provided the performance of the trap is assessed periodically) and can be exposed to harsh environmental conditions. The sensitivity and linearity of the instrument response can be tracked effectively with regular calibrations, increasing confidence in the quality of the data. The instrument has been demonstrated to function as desired in a tropical and temperate forest during two lengthy field campaigns, in particular in summer 2018 in an Oxfordshire forest with near continuous operation for almost 6 months. While this paper focused on using the iDirac for isoprene measurements, the instrument configuration can be changed to target different analytes. Future work will focus on monitoring different VOCs (e.g. dimethyl sulfide, DMS, and ethylene), as well as improving on some of the current limitations of the instrument, such as implementing a more sophisticated and interactive control over the oven temperature. An intercomparison in real ambient air with more established VOC monitoring instrumentation (such as that described by Barket et al., 2001) will also help to better evaluate the accuracy of the iDirac.

Data availability. The data from the Wytham Woods field campaign are available from the Natural Environment Research Council (NERC) Centre for Environmental Data Analysis (CEDA) archive at https://catalogue.ceda.ac.uk/uuid/ 0c39809848ce47bb850d8ca2045e40f2 (last access: 12 February 2020, Ferracci et al., 2020b). The rest of the data presented in this paper are available upon request.

Author contributions. CGB wrote the paper with assistance from VF. CGB, VF and ADR performed the lab work and designed the experiments. ADR built the first prototype instrument. $\mathrm{CB}$ and $\mathrm{VF}$ created the plots. MIM and MSMN assisted with lab work, provided advice and assisted with field deployments. JAP, RLJ and NRPH supervised and provided advice. All authors discussed the results and commented on the paper.

Competing interests. The authors declare that they have no conflict of interest.

Acknowledgements. Conor G. Bolas acknowledges and thanks the Natural Environmental Research Council (NERC) for the Doctoral Training Partnership studentship. We would like to thank Sabine Both of the University of New England, Ully Kritzler of the University of Manchester, and the teams at BALI and SAFE for their support in the field. The authors are grateful to the Malaysian Meteorological Department and Universiti Malaysia Sabah for additional support in Borneo. In addition, the authors wish to thank Yadvinder 
Malhi of the University of Oxford for help with instrument deployment in the Wytham Woods research forest, and Ray Freshwater of the University of Cambridge for his technical expertise. Additionally, the authors would like to gratefully acknowledge Christopher Walton for useful discussions on thermal desorption techniques.

Financial support. The research was supported and funded by the BALI project (grant no. NE/K016377/1).

Review statement. This paper was edited by Hendrik Fuchs and reviewed by two anonymous referees.

\section{References}

Allen, N. D. C., Worton, D. R., Brewer, P. J., Pascale, C., and Niederhauser, B.: The importance of cylinder passivation for preparation and long-term stability of multicomponent monoterpene primary reference materials, Atmos. Meas. Tech., 11, 64296438, https://doi.org/10.5194/amt-11-6429-2018, 2018.

Archibald, A. T., Jenkin, M. E., and Shallcross, D. E.: An isoprene mechanism intercomparison, Atmos. Environ., 44, 5356-5364, https://doi.org/10.1016/j.atmosenv.2009.09.016, 2010.

Barket, D. J., Hurst J. M., Couch, T. L., Colorado, A., Shepson P. B., Riemer D. D., Hills, A. J., Apel, E. C., Hafer, R., Lamb, B. K., Westberg, H. H., Farmer, C. T., Stabenau, R. R., and Zika, R. G.: Intercomparison of automated methodologies for determination of ambient isoprene during the PROPHET 1998 summer campaigns, J. Geophys. Res., 106, 24301-24313, https://doi.org/10.1029/2000JD900562, 2001.

Bauwens, M., Stavrakou, T., Müller, J.-F., Van Schaeybroeck, B., De Cruz, L., De Troch, R., Giot, O., Hamdi, R., Termonia, P., Laffineur, Q., Amelynck, C., Schoon, N., Heinesch, B., Holst, T., Arneth, A., Ceulemans, R., Sanchez-Lorenzo, A., and Guenther, A.: Recent past (1979-2014) and future (2070-2099) isoprene fluxes over Europe simulated with the MEGAN-MOHYCAN model, Biogeosciences, 15, 3673-3690, https://doi.org/10.5194/bg-15-3673-2018, 2018.

Bieri, G., Burger, F., Heilbronner, E., and Maier, J. P.: Valence Ionization Energies of Hydrocarbons, Helv. Chim. Acta, 60, 22132233, https://doi.org/10.1002/hlca.19770600714, 1977.

Carlton, A. G., Wiedinmyer, C., and Kroll, J. H.: A review of Secondary Organic Aerosol (SOA) formation from isoprene, Atmos. Chem. Phys., 9, 4987-5005, https://doi.org/10.5194/acp-9-49872009, 2009.

Carslaw, K. S., Boucher, O., Spracklen, D. V., Mann, G. W., Rae, J. G. L., Woodward, S., and Kulmala, M.: A review of natural aerosol interactions and feedbacks within the Earth system, Atmos. Chem. Phys., 10, 1701-1737, https://doi.org/10.5194/acp10-1701-2010, 2010.

Claeys, M.: Formation of Secondary Organic Aerosols Through Photooxidation of Isoprene, Science, 303, 1173-1176, https://doi.org/10.1126/science.1092805, 2004.

Ferracci, V., Bolas, C. G., Freshwater, R. A., Staniaszek, Z., Jaars, K., Otu-Larbi, F., King, T., Beale, J., Malhi, Y., Waine, T. W., Jones, R. L., Ashworth, K., and Harris, N. R. P.: Continuous isoprene measurements in a UK temperate forest for a whole grow- ing season: effects of drought stress during the 2018 heatwave, Geophys. Res. Lett., submitted, 2020a.

Ferracci, V., Harris, N., Bolas, C., Jones, R., and Staniaszek, Z.: Biodiversity and Land Use Impacts on Tropical Forest Ecosystem Function (BALI): Isoprene concentration measurements at Wytham Woods (UK) during the summer of 2018, available at: https://catalogue.ceda.ac.uk/uuid/ 0c39809848ce47bb850d8ca2045e40f2 (last access: 12 February 2020), Centre for Environmental Data Analysis, 2020 b.

Fu, D., Millet, D. B., Wells, K. C., Payne, V. H., Yu, S., Guenther, A., and Eldering, A.: Direct retrieval of isoprene from satellite-based infrared measurements, Nat. Commun., 10, 3811, https://doi.org/10.1038/s41467-019-11835-0, 2019.

Gostlow, B., Robinson, A. D., Harris, N. R. P., O’Brien, L. M., Oram, D. E., Mills, G. P., Newton, H. M., Yong, S. E., and A Pyle, J.: $\mu$ Dirac: an autonomous instrument for halocarbon measurements, Atmos. Meas. Tech., 3, 507-521, https://doi.org/10.5194/amt-3-507-2010, 2010.

Guenther, A., Karl, T., Harley, P., Wiedinmyer, C., Palmer, P. I., and Geron, C.: Estimates of global terrestrial isoprene emissions using MEGAN (Model of Emissions of Gases and Aerosols from Nature), Atmos. Chem. Phys., 6, 3181-3210, https://doi.org/10.5194/acp-6-3181-2006, 2006.

Hantson, S., Knorr, W., Schurgers, G., Pugh, T. A. M., and Arneth, A.: Global isoprene and monoterpene emissions under changing climate, vegetation, $\mathrm{CO}_{2}$ and land use, Atmos. Environ., 155, 3545, https://doi.org/10.1016/j.atmosenv.2017.02.010, 2017.

Helmig, D., Greenberg, J., Guenther, A., Zimmerman, P., and Geron, C.: Volatile organic compounds and isoprene oxidation products at a temperate deciduous forest site, J. Geophys. Res.Atmos., 103, 22397-22414, https://doi.org/10.1029/98JD00969, 1998.

Jones, C. E., Hopkins, J. R., and Lewis, A. C.: In situ measurements of isoprene and monoterpenes within a south-east Asian tropical rainforest, Atmos. Chem. Phys., 11, 6971-6984, https://doi.org/10.5194/acp-11-6971-2011, 2011.

Langford, B., Misztal, P. K., Nemitz, E., Davison, B., Helfter, C., Pugh, T. A. M., MacKenzie, A. R., Lim, S. F., and Hewitt, C. N.: Fluxes and concentrations of volatile organic compounds from a South-East Asian tropical rainforest, Atmos. Chem. Phys., 10, 8391-8412, https://doi.org/10.5194/acp-10-8391-2010, 2010.

Lehning, A., Zimmer, I., Steinbrecher, R., Bruggemann, N., and Schnitzler, J. P.: Isoprene synthase activity and its relation to isoprene emission in Quercus robur L. leaves, Plant Cell Environ., 22, 495-504, https://doi.org/10.1046/j.1365-3040.1999.00425.x, 1999.

Liu, J., D’Ambro, E. L., Lee, B. H., Lopez-Hilfiker, F. D., Zaveri, R. A., Rivera-Rios, J. C., Keutsch, F. N., Iyer, S., Kurten, T., Zhang, Z., Gold, A., Surratt, J. D., Shilling, J. E., and Thornton, J. A.: Efficient Isoprene Secondary Organic Aerosol Formation from a Non-IEPOX Pathway, Environ. Sci. Technol., 50, 9872-9880, https://doi.org/10.1021/acs.est.6b01872, 2016.

Nadzir, M. S. M., Cain, M., Robinson, A. D., Bolas, C., Harris, N. R. P., Parnikoza, I., Salimun, E., Mustafa, E. M., Alhasa, K. M., Zainuddin, M. H. M., Ghee, O. C., Morris, K., Khan, M. F., Latif, M. T., Wallis, B. M., Cheah, W., Zainudin, S. K., Yusop, N., Ahmad, M. R., Hussin, W. M. R. W., Salleh, S. M., Hamid, H. H. A., Lai, G. T., Uning, R., Bakar, M. A. A., Ariff, N. M., Tuah, Z., Wahab, M. I. A., Foong, S. Y., Samah, A. 
A., Chenoli, S. N., Wan Johari, W. L., Zain, C. R. C. M., Rahman, N. A., Rosenstiel, T. N., Yusoff, A. H., Sabuti, A. A., Alias, S. A., and Noor, A. Y. M.: Isoprene hotspots at the Western Coast of Antarctic Peninsula during MASEC'16, Polar Sci., 20, 63-74, https://doi.org/10.1016/j.polar.2018.12.006, 2019.

Nölscher, A. C., Yañez-Serrano, A. M., Wolff, S., de Araujo, A. C., Lavrič, J. V, Kesselmeier, J., Williams, Jlscher, A. C., Yañez-Serrano, A. M., Wolff, S., de Araujo, A. C., Lavrič, J. V, Kesselmeier, J., and Williams, J.: Unexpected seasonality in quantity and composition of Amazon rainforest air reactivity., Nat. Commun., 7, 10383, https://doi.org/10.1038/ncomms10383, 2016.

Otu-Larbi, F., Bolas, C. G., Ferracci, V., Staniaszek, Z., Jones, R. L., Malhi, Y., Harris, N. R. P., Wild, O., and Ashworth, K.: Modelling the effect of the 2018 summer heatwave and drought on isoprene emissions in a UK woodland, Glob. Chang. Biol., 14963, 1-16, https://doi.org/10.1111/gcb.14963, 2019.

Peters, R. and Bakkeren, H.: Sorbents in Sampling. Stability and Breakthrough Measurements, Analyst, 71-74, 1994.

Rhoderick, G. C., Cecelski, C. E., Miller, W. R., Worton, D. R., Moreno, S., Brewer, P. J., Viallon, J., Idrees, F., Moussay, P., Kim, Y. D., Kim, D., Lee, S., Baldan, A. and Li, J.: Stability of gaseous volatile organic compounds contained in gas cylinders with different internal wall treatments, Elementa, 7, 28, https://doi.org/10.1525/elementa.366, 2019.

Robinson, A. D., Millard, G. A., Danis, F., Guirlet, M., Harris, N. R. P., Lee, A. M., McIntyre, J. D., Pyle, J. A., Arvelius, J., Dagnesjo, S., Kirkwood, S., Nilsson, H., Toohey, D. W., Deshler, T., Goutail, F., Pommereau, J.-P., Elkins, J. W., Moore, F., Ray, E., Schmidt, U., Engel, A., and Müller, M.: Ozone loss derived from balloon-borne tracer measurements in the 1999/2000 Arctic winter, Atmos. Chem. Phys., 5, 1423-1436, https://doi.org/10.5194/acp-5-1423-2005, 2005.
Sharkey, T. D.: Is it useful to ask why plants emit isoprene?, Plant Cell Environ., 36, 517-520, https://doi.org/10.1111/pce.12038, 2013.

Sharkey, T. D., Wiberley, A. E., and Donohue, A. R.: Isoprene emission from plants: Why and how, Ann. Bot., 101, 5-18, https://doi.org/10.1093/aob/mcm240, 2008.

Smith, I. M.: Software for Determining Polynomial Calibration FUnctions by Generalised Least Squares: User Manual, NPL Rep. MS11, Teddingt., 1-22, 2010.

Squire, O. J., Archibald, A. T., Griffiths, P. T., Jenkin, M. E., Smith, D., and Pyle, J. A.: Influence of isoprene chemical mechanism on modelled changes in tropospheric ozone due to climate and land use over the 21st century, Atmos. Chem. Phys., 15, 5123-5143, https://doi.org/10.5194/acp-15-5123-2015, 2015.

Stone, D., Evans, M. J., Edwards, P. M., Commane, R., Ingham, T., Rickard, A. R., Brookes, D. M., Hopkins, J., Leigh, R. J., Lewis, A. C., Monks, P. S., Oram, D., Reeves, C. E., Stewart, D., and Heard, D. E.: Isoprene oxidation mechanisms: measurements and modelling of $\mathrm{OH}$ and $\mathrm{HO}_{2}$ over a South-East Asian tropical rainforest during the OP3 field campaign, Atmos. Chem. Phys., 11, 6749-6771, https://doi.org/10.5194/acp-11-6749-2011, 2011.

Visakorpi, K., Gripenberg, S., Malhi, Y., Bolas, C., Oliveras, I., Harris, N., Rifai, S., and Riutta, T.: Small-scale indirect plant responses to insect herbivory could have major impacts on canopy photosynthesis and isoprene emission, New Phytol., 220, 799810, https://doi.org/10.1111/nph.15338, 2018.

Yáñez-Serrano, A. M., Nölscher, A. C., Williams, J., Wolff, S., Alves, E., Martins, G. A., Bourtsoukidis, E., Brito, J., Jardine, K., Artaxo, P., and Kesselmeier, J.: Diel and seasonal changes of biogenic volatile organic compounds within and above an Amazonian rainforest, Atmos. Chem. Phys., 15, 3359-3378, https://doi.org/10.5194/acp-15-3359-2015, 2015. 